\title{
Application of Online Teaching to Project-Based Education
}

\author{
Xiaotie Niu ${ }^{1, a}$, Aiqing Chen ${ }^{2, b}$ \\ ${ }^{1}$ Department of Mechanical and Electrical Engineering, Beijing Polytechnic College, Beijing, \\ 100042, China \\ ${ }^{2}$ Department of Mathematics,Jiaozuo Teachers College,Jiaozuo, 454000,China

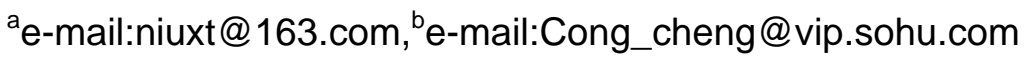

Keywords: Online Teaching;Project-based Education;Project Education

\begin{abstract}
To promote extensive application of auxiliary online teaching among higher vocational colleges, and improve the ability and personal quality of students, this thesis aims to discuss major functions of BlackBoard and project-based education methods in combination with further deepening of auxiliary online teaching among higher vocational colleges, which serves as a beneficial practice for aforesaid purpose.
\end{abstract}

\section{Introduction}

Auxiliary online teaching has been gradually promoted in some colleges accompanied by continuous elevation of information level. Presently, the approach to bring into play of roles of online teaching platform in extensive project-based education in higher vocational colleges, and thus improving learning skills, is still a new subject. The writer once tried to incorporate Blackboard, the auxiliary online teaching platform into the project education for the purpose of accomplishing various tasks at such stages as knowledge explanation, conceptual design, project implementation as well as assessment and summary when giving lessons on Photoshop.

\section{Project Introduction}

Project teaching refers to a teaching activity conducted through joint implementation of one certain "project" by the teacher and students. Students are the learning subject in the whole teaching process; whereas the teacher acts as an "instructor" for organization, guidance and handling of queries instead of a "tutor" . Currently, project-based targeting at cultivation of professional skills of students is being promoted among higher vocational colleges. Blackboard serves as the most frequently used online teaching platform in universities, which is actually a suppositional teaching environment for initiative learning by students based on the teaching contents provided. It can overcome such disadvantages as limited conventional teaching hours and information to extend the learning process, and ensure integrity of knowledge hierarchy.

To enable students to command knowledge points in a profound and systematic manner, and apply knowledge obtained to practical work, a practical teaching has been carried out after teaching of basic knowledge on the Background, Layer, Route, Masking and tools associated with Photoshop.

Design and preparation of poster entitled "The Case for Reform of Cultivation of Mechanical and Electrical Talents" serves as the subject of the project teaching (Table 1). This subject is in consideration of 4 aspects: As students in the same college might be influenced by such concepts as "order design", "class establishment", "teaching within the campus" and "practice on post" of mechanical and electrical engineering, it is easy for them to understand implications of cultivation of talents, design the poster in a short possible time, and focus their attentions on realization of technologies.Due to strict requirements for time and quality concerning design of commercial display board, it is relatively difficult for students at the learning stage to accomplish the task within a short time.As the application of skill in design of poster with the help of Photoshop is extremely universal, it should be commanded by all designers in either small stalls or big advertisement companies.This project covers all contents of this course, which is available for systematic and 
profound linking of all knowledge points.

Table 1. Arrangement for the Project Entitled "The Case for Reform of Cultivation of Mechanical and Electrical Talents"

\begin{tabular}{|c|l|}
\hline \multirow{3}{*}{ Contents } & $\begin{array}{l}\text { Design and preparation of poster entitled "The Case for Reform of Cultivation } \\
\text { of Mechanical and Electrical Talents" with the help of Photoshop features in } \\
\text { comprehensive manifestation of process, approaches and results of talent cultivation } \\
\text { and high publicity. }\end{array}$ \\
\hline Objective & $\begin{array}{l}\text { Knowledge and skills: Command setting of properties and creation methods } \\
\text { concerning background, Layer, route, masking and pen of Photoshop. } \\
\text { Emotion and attitude: Comprehend procedures and methods for preparation of } \\
\text { poster, cultivate aesthetic judgment ability and attitude of esteem, equality and } \\
\text { fairness, and enhance team spirit. }\end{array}$ \\
\hline
\end{tabular}

\section{Knowledge Explanation}

Knowledge explanation covers two parts, namely knowledge points on Photoshop and project (i.e. preparation of poster) conception.

Students can only command the use of such tools as Layer, Masking, Pen, Type and Gradient other than skillful application through preliminary teaching. Therefore, teachers are requested to make a further explanation of knowledge points in the project, especially tools and masking and other tools that are difficult for understanding. As proved by facts, conceptual explanation is not enough. Students are inclined to accept practical effect as created in combination with database provided by the Blackboard platform.

Analysis of project conception, namely design of poster contents covers the following three aspects:Critical procedures for order cultivation: "preparation of order cultivation plan", "establishment of order class", "internal order teaching” and "practice in enterprises"; The most critical safeguard measures for each step;Successful cases for reform of talent cultivation, such as "Beijing Fine Carving Order Class” and "Kunming CRCC Order Class”.

As literal description of four steps and safeguard approaches for "Reform of Cultivation of Mechanical and Electrical Talents" as well as group photos of teachers and students of order class can be exhibited on the Blackboard platform before teaching, it can facilitate teachers to make an easy and explicit explanation within 3-5 minutes. This is favorable for easy understanding of core contents of the poster by students.

\section{Project Design}

It mainly targets at grouping of students and assign of tasks for each team.

36 students in Online Class 0831 are relegated into 7 learning teams by teachers and subject representatives through negotiations based on their previous scores in professional courses before teaching. Each team is composed of students at excellent, good, medium, acceptable and unacceptable levels. This aims to relegate students of equivalent ability into the same team. The term of alternating team leader is defined in reference to project period to cultivate ability of each student in organization, operation, design, work division and inquiry.

Tasks of such 7 teams are stated as follows: Design and prepare poster entitled "The Case for Reform of Cultivation of Mechanical and Electrical Talents” according to project requirements. Teachers would make a further division of tasks for poster preparation to mobilize all members in the team: Overall background design,Design of 4 steps for order cultivation,Design of safeguard measures,Design of talent cultivation effect,Task synthesis. Each team member is requested to accomplish at least one task; whereas final work is to be submitted by the team leader.

Team members would engage in discussion, collection of various pictures and data as well as stipulation of preparation plan once the task is defined. The team leader is responsible for 
reasonable work division among team members; whereas teachers would provide instructions in this process. It is unlikely to find all problems with students, and complete poster preparation within 2 class hours. Therefore, more tasks are to be accomplished based on the Blackboard:

Teachers are requested to check if internal communication records of the team and interaction rules as defined by coordination team are optimal, monitor schedule of tasks of the team at any time, inquire into focus of all members on the project through review their performance on the platform, collect common difficult problems with students, and establish FAQ database on the platform (it is applicable to request students to accomplish the task of FAQ) so as to ensure integral learning both in and outside classroom.

On the other hand, students can put forward questions on the platform at any time, proactively answer questions by others, express their learning experience, share valuable elements through dynamic evaluation of teaching process in the dummy classroom. Various communication activities are favorable for mobilization of enthusiasm of students in participation in teaching activities and cultivation of their individualized thinking. The platform-based discussion may provide diversified modes and tools for FAQ among teachers and students.

\section{Project Implementation}

Firstly, define subject of poster and approaches for application of colors and graphic fonts, and specify design elements before workout of draft in combination with photos and literal information collected from Blackboard based on the defined subject. Finally, define dimension and background of photos to establish layer elements gradually.

Project implementation gives priority to direction of students:Poster design is requested to realize adequate visual impact through collocation of photos and colors;Contents of poster should be precise, which can grasp major appeals, namely exhibition of contents for reform of talent cultivation other than exaggerated and deluged photos;Literal contents should be appropriate in proportion, which should give priority to photos as supplemented by text; The title text should be unique and striking; whereas photos and text should be in reasonable arrangement and collocation. It is applicable to provide some excellent design drafts on the Blackboard platform for appreciation by students so as to enable them to seek their creation inspiration.

Teachers are requested to proceed with routine instructions in the classroom, and focus their attentions on the Blackboard-based discussion forums and dummy classroom after class during project implementation. This aims to realize diversified information transfer between teachers and students, teachers and teachers, students and students, students and network as well as teachers, students and society so as to make a transition from teaching to coordinated and interactive learning as well as settlement of various questions put forward by students, and realize role transfer from the campus and working environment.

\section{Assessment and Summary}

According to previous project-based teaching, works are normally presented in the classroom for requesting teachers and students to put forward revision propositions. Presently, many works are presented on the blackboard at early stage to enable students to freely express their opinions on the discussion forum. All works exhibited in the classroom through repeated optimization are normally of high quality, which can features in twice the result with half the effort. Finally, the team leader would report overall project design process and solutions to critical problems, and assign tasks of each member. Any student can put forward questions freely for answers by the team leader or other members.

Project assessment is an important link of project teaching, which aims at comprehensive assessment of engagement degree, coordination ability, team spirit and achievements of students during project implementation by means of individual assessment, judgment by the team leader, mutual assessment and judgment by teachers.

To ensure assessment objective, teacher may make a judgment in reference to performance of students on the Blackboard platform, such as frequency of speeches on the forum, course learning, online homework, work schedule, provision of elements and learning review. The assessment 
known as "verbal data" is more effective. Eventually, teachers would put forward common problems and solutions to direct interactive learning of students for simultaneous improvement.

\section{Conclusion}

People have always been focusing on the specific modes of auxiliary online teaching and teaching quality. Establishment of an affective teaching method and implementation environment has direct impacts on learning effect. Online platform can play an effective role in auxiliary teaching in terms of project teaching, course teaching, preparation before class, review after class, assignment of homework as well as test and assessment. However, Blackboard is only a platform after all, which is in need of abundant reserve of teaching resources to be prepared by teachers. We know quite well that online teaching is a challenge to conventional teaching modes, which requires repeated attempts and tremendous efforts on the part of administration personnel, teachers and students.

\section{References}

[1] Xu Han, Theoretical Basis and Fundamental Features of Project Teaching and Requirements for Teachers [J], Vocational Education Forum, 2007 (3) : 9-12

[2] Wang Li, Reform of Vocational Education Course in the Mode of "Project Teaching" [J], Secondary Vocational Education, 2010 (8) : 3-5

[3] Wu Yunming, Teaching Design and Practice of 3D Computer Animation Based on Project Teaching [J], Modern Computer, 2010 (12) : 51-53

[4] Zhang Shuting, Brief Discussion on Application of Project Teaching Method in Authorware Teaching, Journal of Education Institute of Taiyuan University, 2010 (7) : 104-106

[5] Li Ruixing, Study of Teaching Applications in Higher Polytechnic Colleges Based on Case Teaching Method [J], Study of Higher Education, 2010（8） : 173-174 